\title{
NEW DATA ABOUT THE INITIATE TIME OF THE PRE-URAL (KARGALY) MINING AND METALLURGICAL CENTER ${ }^{1}$
}

\author{
Nina L. Morgunova
}

Orenburg State Pedagogical University, Orenburg, Russian Federation

\author{
Airat A. Faizullin \\ Orenburg State Pedagogical University, Orenburg, Russian Federation
}

\begin{abstract}
The article summarizes the data on the initial stage of metal production in the Southern Urals of the Bronze Age. Lots of Yamnaya culture burial mounds with copper items inside were excavated near the Kargaly deposit in the Orenburg oblast. The variety and originality of tools forms indicate the independent nature of the Ural metallurgy in the early Bronze Age. The authors present new data that allows us to reconstruct the process of metal production at the Repin (early) stage of the Yamnaya culture and explain the beginning of this process by the development of the Kargaly copper ore deposit. Excavations of the Turganik settlement were carried out. Cultural layer 5 of the early Bronze Age is dated to $3800-3360 \mathrm{cal} \mathrm{BC}$. It is characterized by ceramics and other artefacts of the Repin type. Fragments of Kargaly copper ore, slags and copper tools (knife, awls) were found in the layer. The traceological analysis of about approximately 100 items made of stone and animal bones was performed. 41 of them are related to metallurgy and metalworking. They represent tools of all metallurgical production stages, starting from metal extraction from ore to the processing of the finished copper product. Functional groups of products such as ore mortar, ore crushing hammers, casting molds, forging hammers, anvils, edges leveling tools, sharpening stones, and others have been identified. Stone artifacts from the burials were also studied, including ore crushing and forging hammers. No mining tools were found at the settlement. It is concluded that the ore was extracted and processed at the Kargaly deposit, located $70 \mathrm{~km}$ to the east, and then delivered to the settlement as an enriched concentrate. The settlement was seasonal. Metallurgical activity here took its place in the summer, since the main $\widetilde{\widetilde{C}}$ type of economic activity was nomadic pastoralism.

Key words: metallurgy and metalworking, technical analysis, Yamnaya culture, Kargaly deposit, Southern Urals.

Citation. Morgunova N.L., Faizullin A.A., 2021. Novye dannye o nachale funktsionirovaniya Priural'skogo (Kargalinskogo) gorno-metallurgicheskogo tsentra [New Data About the Initiate Time of the Pre-Ural (Kargaly) Mining and Metallurgical Center]. Nizhnevolzhskiy Arkheologicheskiy Vestnik [The Lower Volga Archaeological Bulletin], vol. 20, no. 1, pp. 5-19. DOI: https://doi.org/10.15688/nav.jvolsu.2021.1.1
\end{abstract}




\title{
НОВЫЕ ДАННЫЕ О НАЧАЛЕ ФУНКЦИОНИРОВАНИЯ ПРИУРАЛЬСКОГО (КАРГАЛИНСКОГО) ГОРНО-МЕТАЛЛУ РГИЧЕСКОГО ЦЕНТРА ${ }^{1}$
}

\author{
Нина Леонидовна Моргунова \\ Оренбургский государственный педагогический университет, г. Оренбург, Российская Федерация \\ Айрат Асхатович Файзуллин \\ Оренбургский государственный педагогический университет, г. Оренбург, Российская Федерация
}

\begin{abstract}
Аннотация. В статье обобщаются данные о начальном этапе металлопроизводства на Южном Урале в бронзовом веке. В Оренбургской области в непосредственной близости от Каргалинского месторождения было раскопано множество курганов ямной культуры, в которых найдены медные изделия. Разнообразие и оригинальность форм орудий свидетельствуют о самостоятельном характере приуральской металлургии в раннем бронзовом веке. Авторы представляют новые данные, позволяющие реконструировать процесс металлопроизводства на репинском этапе ямной культуры и связать начало этого процесса с освоением Каргалинского месторождения медной руды. Проведены раскопки Турганикского поселения. Культурный слой 5 раннего бронзового века датирован 3800-3360 cal BC. Он характеризуется керамикой и другими артефактами репинского типа. В слое найдены фрагменты медной руды из каргалинских источников, шлаки и медные орудия (нож, шилья). Проведен трасологический анализ около 100 макроизделий из камня и предметов из костей животных. Из них 41 предмет связан с металлургией и металлообработкой. Они представляют орудия, предназначенные для всех этапов металлургического производства - от получения металла из руды до завершения оформления и обработки готового медного изделия. Выделены такие функциональные группы изделий, как рудотерки, молоты для дробления руды, литейные формы, кузнечные молоты, наковальни, орудия для выравнивания граней, оселки и др. Также изучены каменные артефакты из погребений, среди которых обнаружены молоты для дробления руды и кузнечной обработки. На поселении не найдены горнопроходческие орудия. Сделан вывод, что руда добывалась и обрабатывалась на Каргалинском месторождении, расположенном в 70 км к востоку, и доставлялась на поселение в виде обогащенного концентрата. Поселение было сезонным. Металлургическая деятельность здесь проходила в летнее время, так как основным видом хозяйственной деятельности являлось подвижное скотоводство.

Ключевые слова: металлургия и металлообработка, трасологический анализ, ямная культура, Каргалинское месторождение, Южное Приуралье.

Цитирование. Моргунова Н. Л., Файзуллин А. А., 2021. Новые данные о начале функционирования Приуральского (Каргалинского) горно-металлургического центра // Нижневолжский археологический вестник. Т. 20, № 1. С. 5-19. DOI: https://doi.org/10.15688/nav.jvolsu.2021.1.1
\end{abstract}

\section{Введение}

Впервые о начальном этапе функционирования Приуральского горно-металлургического центра (ГМЦ) на базе Каргалинского месторождения медной руды вблизи г. Оренбурга было заявлено в работах 60-х годах XX века. Его деятельность была увязана с ямной культурой после находок уникальных предметов в могильнике Увакском [Федорова-Давыдова, 1962; Черных, 1966]. Однако долгое время роль Приураль- ского ГМЦ в системе Циркумпонтийской металлургической провинции (ЦМП) оценивалась как слабая и второстепенная в сравнении с таким гигантом металлопроизводства того времени, как майкопский ГМЦ в Предкавказье [Черных, 1970; Рысин, 2007].

Тем временем, начиная с 70-80-х гг. $\mathrm{XX}$ в., накапливались материалы, говорящие об обратном. В последние десятилетия в курганах ямной культуры в Самарской и Оренбургской областях было обнаружено 
Н.Л. Моргунова, А.А. Файзуллин. Новые данные о начале функционирования Приуральского ГМЦ

значительное число металлических изделий, включая металлоемкие орудия труда и оружие [Васильев и др., 2000; Моргунова, 2014]. В Оренбургском Приуралье в непосредственной близости от Каргалинского месторождения были раскопаны десятки курганов ямной культуры, в том числе курганы больших размеров [Моргунова, Файзуллин, 2018]. Именно в последних найдены медные изделия, во многих случаях - наборами по несколько различных предметов (рис. 1). Наряду с привычными формами находились оригинальные предметы, не имеющие прямых аналогий не только в пределах ямной области, но и в других культурах РБВ. В результате этих целенаправленных исследований ямных памятников количество медных предметов значительно возросло. По количеству, ассортименту и оригинальности металла памятники волгоуральского варианта ямной культуры и особенно его приуральской группы значительно превзошли все другие варианты на огромном пространстве ямной общности. Множество оригинальных изделий можно считать изобретениями приуральских мастеров. К таковым следует отнести, например, биметаллические изделия, втульчатые долота, оригинальные формы топоров, наконечник копья и др. (рис. 2,1-12).

Металл был обнаружен в погребениях всех этапов ямной культуры, включая комплексы репинского времени. Проведены исследования по определению состава металла и технологии производства изделий металлопроизводства ямной культуры Южного Приуралья [Орловская, 1994; Дегтярева, 2010]. Однако вплоть до последнего времени вопросы определения хронологии как раннего этапа ямной культуры, так и начала собственного металлопроизводства оставались дискуссионными. Кроме того, отсутствовали прямые доказательства связи разработок Каргалинского месторождения с металлопроизводством ямной культуры на ее раннем этапе.

В задачи данной статьи входит представление новых данных, полученных авторами за последние годы, которые позволяют достаточно уверенно ответить на поставленные вопросы.

\section{Свидетельства металлургии и металлообработки в артефактах из памятников ямной культуры Волго-Уралья \\ и на Каргалинских рудниках}

Долгое время единственными свидетельствами о собственном металлопроизводстве в ямной культуре Волго-Уралья являлись находки из погребальных комплексов (рис. 2). Особенно многочисленными они были в курганах развитого этапа. В памятниках репинского времени они по сей день остаются единичными и достаточно однообразными по формам изделий (ножи, шилья). Это погр. 2 кург. 4 Герасимовка II, где наряду с типичным сосудом репинского облика найдено 8 медных изделий, включая нож, шило и мелкие украшения (рис. 2,18-20). В Самарском Поволжье в погр. 1 кург. 17 КМ Покровка наряду с рогатой булавкой-амулетом найдены медный нож и шило (рис. 2,2122). На территории Нижнего Поволжья известен комплекс из погр. 3 в кург. 5 Скатовка с тремя сосудами репинского типа и медными изделиями (нож и шило). Все названные предметы были изготовлены из металла группы «медистые песчаники» (МП) [Черных, 1966, с. 126; Васильев и др., 2000; Дегтярева, 2010].

Очевиден факт, что наибольшее число курганов ямной культуры с находками медных изделий расположены по периферии ближайших источников руды с подобным составом металла - вокруг Каргалов (рис. 1). Однако как на самом месторождении, так и на памятниках ямного времени данные о самом процессе металлопроизводства до последнего времени не были известны. В основном на Каргалах обнаружены поселения и курганы горняков и металлургов срубной культуры. Поселения, связанные с металлургической деятельностью ямной культуры на Каргалах, пока не выявлены. В то же время в пределах рудников исследованы погребения ямной культуры в КМ Уранбашский и КМ Першин, в том числе захоронение с литейной формой для отливки топоров утевского типа [Каргалы, 2005, c. 29-35, 100]. Эти комплексы относятся уже к концу развитого этапа. О начале добычи медной руды в более раннее время говорит 
единственный, но далеко не бесспорный факт. Это ${ }^{14} \mathrm{C}$ дата, полученная из нижнего слоя разреза древней разведочной шахты на поселении Горный (4955 \pm 165 BP, 3960-3630 cal BC) [Каргалы, 2004, с. 295-297].

В последние годы появились новые данные. Так, в районе Каргалов и на других меднорудных объектах Оренбуржья осуществляется большой проект по изучению горного дела в бронзовом веке под руководством В.В. Ткачева и С.В. Богданова. По предварительным сообщениям, ими получены материалы, подтверждающие связь основной части металла из ямных погребений региона с источниками медной руды в Приуралье [Богданов, 2019].

Нами также получены весьма значимые данные, говорящие о начальном моменте становления металлопроизводства в Приуралье на Турганикском поселении, расположенном в 70 км к западу от Каргалинского ГМЦ в устье р. Турганик (правый приток р. Ток, бассейн р. Самара) [Моргунова и др., 2017]. Они достаточно красноречиво показали, что освоение Каргалинского месторождения связано с начальным, репинским этапом формирования ямной культуры.

Исследовано около 900 кв. м площади поселения. Находки раннего бронзового века в основном были сосредоточены в северной части раскопа и в слое 5 , располагавшемся выше слоя 6 эпохи энеолита. Материалы включали многочисленные фрагменты и развалы сосудов репинского типа, изделия из камня макролитических форм, кости животных. Кроме того, с комплексом были связаны находки медных предметов - подвеска из проволоки в 2 оборота, обломок типичного ямного ножа и 3 шила (рис. 2,13-17). Важным показателем для определения культурной принадлежности и хронологии слоя стала также рогатая булавка-амулет (рис. 5,8).

Радиоуглеродное датирование керамики и костей животных (всего получено $14{ }^{\mathrm{C}} 14$ дат: по керамике -2 , костям животных - 12) указало на интервал времени в промежутке между $4530 \pm 30$ ВР до $5064 \pm 100$ ВР [Моргунова и др., 2017]. Калиброванный интервал в одну сигму устанавливается в пределах 3966-

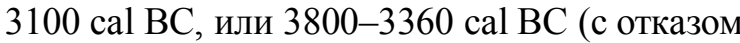
от самой ранней и от самой поздней дат).
Особенно показательны такие находки в слое 5 Турганикского поселения, как кусочки руды и шлаки. Их специальное исследование позволило сделать вывод, что местные мастера-металлурги наряду с рудами Каргалинского месторождения использовали также руды из месторождений Южного Урала типа Ишкининского, расположенного к западу от г. Орска [Богданов, 2019, с. 165].

Но наиболее значительные ответы на поставленные в данной статье вопросы дали результаты трасологического анализа, примененного в изучении достаточно массовых находок макролитических предметов из слоя бронзового века Турганикского поселения. По типологии они напоминали многие из форм каменных макроорудий поселения Михайловка II (средний слой репинского времени) в Поднепровье, связь которых с металлургическими и кузнечными операциями в результате трасологических исследований в свое время успешно доказана Г.Ф. Коробковой [Коробкова, Шапошникова, 2005, с. 190-196]. Эти сопоставления дали нам повод обратиться к аналогичным исследованиям.

\section{Каменные и костяные орудия металлопроизводства из слоя репинского времени Турганикского поселения}

Итоги исследований поселения за все годы подробно рассмотрены в коллективной монографии [Моргунова и др., 2017]. Однако трасологическое исследование каменных макроизделий было проведено позже - в начале 2020 года. Полученные результаты кардинальным образом изменили наше представление о назначении данных предметов.

Трасологический анализ каменных и костяных орудий из коллекции Турганикского поселения проведен И.В. Горащуком (г. Самара). Готовится совместная, полная публикация результатов данного исследования, где будут даны все необходимые иллюстрации, включая микрофотографии, и статистические данные. В данной статье ставится задача суммировать полученные данные в связи с поставленными выше вопросами.

Выборка для исследования включала 71 каменное изделие из нерасщепленного сы- 
рья (галек, плиток и кусков камня) и 25 изделий из кости. Из них 37 каменных и 4 костяных предмета определены как орудия для металлургии и металлообработки. Причем практически все они найдены в слое 5 и по определению участвовали на всех этапах металлургического производства - от получения металла из руды до завершения оформления и обработки готового медного изделия.

Орудия для металлургии и металлопроизводства. Они представлены различными видами, типами и подтипами. Мы же в данной статье не будем вдаваться во все тонкости типологической и функциональной классификации, а только назовем основные виды орудий, подчеркнув этапы всего процесса металлопроизводства, начиная от момента получения металла и до конечной обработки готовых изделий.

Первый тип орудий представлен рудотеркой, внутри емкости которой происходило измельчение руды при создании шихты (рис. 3,4$)$. От рудотерки с Турганикского поселения сохранился кусок, по всей вероятности, боковой поверхности крупной конкреции сливного песчаника (кварцита), крупнозернистого, относительно рыхлого, розового цвета. Изготовлена она была с помощью долотовидного металлического орудия с овальным желобчатым лезвием, которым было выдолблено чашевидное углубление.

Ко второму типу относятся 3 молота для дробления руды. Они все идентичны друг другу по характеру износа. На рабочих поверхностях молотов обнаружены микровыбоины от ударов (рис. 3,1-3). Материалом для их изготовления являлся галечник сливного песчаника разной плотности. Молоты делятся на два подтипа по характеру закрепления в работе. Первые крепились с помощью Т-образной рукояти, а для вторых применялось ручное удержание. Эти различия проявляются не только в морфологии артефактов, но и в способах их обработки.

Молоты, закрепленные на рукояти, имеют овальное или овально-уплощенное сечение. Это нужно для того, чтобы молот плотно прилегал к рукояти. Кроме того, предметы имеют выраженный перехват. В одном случае для придания гальке из кварцита необходимой формы она была расколота продольно, за счет этого было достигнуто уплощение прилегающей к рукояти поверхности. Пикетажем были затуплены острые края в месте перехвата. Сделано это для того, чтобы наметить перехват и притупить край, который могли при нагрузках перерезать стягивающие ремни (рис. 3,1 ). Во втором случае была подобрана специально галька грушевидной формы с уже намеченным перехватом (рис. 3,2).

Молот с ручным удержанием имеет округлое сечение, что, видимо, было удобнее при обхвате рукой (рис. 3,3). Интересно то, что чем меньше вес гальки, тем больше степень ее изношенности. Видимо, так компенсировался недостаток веса инструмента силой удара.

С группой орудий для получения металла связаны 3 сопла из трубчатых костей и обломок старательского совка (рис. 5,9-11).

Важным свидетельством металлургического процесса на поселении являются литейные формы. Они однотипны, представлены тремя фрагментами, изготовлены из алевролита и имеют корытообразные очертания в профиле (рис. 3,5-7). Все формы использовались для литья металлических стержней. Установлено, что во всех случаях расплавленный металл многократно затекал в поры и трещины форм, что говорит о том, что формы не подвергались ремонту. При подобном литье в форме образуются пузыри воздуха, при контакте окисляющие металл, а поверхность отливки имеет бугристый вид. Отсюда следует, что отливалось не изделие, а заготовка для ковки, из чего И.В. Горащуком сделан вывод, что при изготовлении медных вещей кузнечные и слесарные операции превалировали над литьем. Эта реконструкция соответствует данным металлографического анализа металла из погребений ямной культуры Приуралья [Дегтярева, 2010, с. 24-59].

Орудия для металлообработки, кузнечной и слесарной обработки отлитых заготовок. Этот комплекс представлен 28 различными изделиями из камня.

Большую группу из 13 предметов составляют кузнечные молоты. Выделены молоты из гальки естественно треугольных или трапециевидных очертаний, а также молоты иных конфигураций, имеющие естественные выпуклости или канавки на поверхности, которые делали возможным крепление каменно- 
го бойка к рукояти (рис. 4,1-9). Таким образом, галька подбиралась таких конфигураций, чтобы ее было удобно крепить к рукояти. Об этом свидетельствуют следы от стягивания ремнями или шнурами в естественных точках выпуклости либо в канавках поверхностей орудия. Конкретных же форм и наборов такой конфигурации могло быть много.

Для изготовления орудий подбирался плотный сливной песчаник (кварцит). Только в двух случаях это окремневшее дерево (рис. 4,7 ) и кремнистый известняк (рис. 4,4 ). Интересно, что заготовка из кремнистого известняка служила изначально наковальней. Но из-за функционального износа наковальня была разрушена, из ее краевой части был изготовлен кузнечный молот.

К орудиям по кузнечной обработке относятся и наковальни. Они обнаружены в 2 экземплярах с учетом обломка наковальни, из которой был изготовлен кузнечный молот. Наковальни двух видов. Первый - массивное орудие, очертаниями напоминающее параллелепипед (рис. 4,10). На верхней поверхности, судя по следам сработанности, производилась проковка, нижняя поверхность была закреплена в деревянном пазе-гнезде. Экспериментальные данные, полученные И.В. Горащуком, показывают, что на надежно закрепленной наковальне, независимо от ее размеров, можно было производить большой спектр кузнечных операций.

Во всех случаях выявлен износ, характерный для ковки металла, как молотов, так и наковален. Свидетельством данного процесса являются изменение цвета поверхности и фиксация следов температурных трещин и выщерблин. Как на наковальнях, так и на молотах имеются следы термических повреждений поверхности, что говорит о производстве ковки по разогретому металлу. В порах наковален обнаружены микрочастицы окисленного металла. Во всех случаях зафиксированы пятна выглаженной поверхности.

Судя по форме и размерам наковален, логично полагать, что наковальни несли различную функциональную нагрузку. Массивные наковальни могли служить для вытягивания и проковки больших масс металла, а небольшие - для подправки лезвий орудий, окончательной доводки изделий.
Следующий тип кузнечных инструментов - кузнечные гладилки (рис. 4,13). Выявлено два таких орудия. Поверхности металлических изделий эпохи ранней бронзы идеально выглажены. Это достигалось с помощью кузнечных гладилок на стадии кузнечной обработки металла, размягченного под температурным воздействием. Орудия изготавливались из тщательно выровненных плиток и кусков алевролита. Именно ровной стороной и производилась обработка материала. Износ на рабочей поверхности свидетельствует о том, что данные орудия применялись в кузнечной обработке. Это прежде всего сильные термические повреждения предмета в местах соприкосновения поверхности гладилки и раскаленного металла, а также выровненный микрорельеф поверхности, на котором фиксируют параллельные борозды линейных следов.

К слесарным инструментам отнесены следующие типы орудий.

Брусковые оселки - орудия для заточки и подправки лезвий металлических орудий (рис. 4,12). Функциональный износ инструмента обнаружен на локальных участках и плоскости на поверхности изделий, изглаженных при обработке металла. При заточке лезвия использовались различные участки и различные положения оселка в работе.

Плитчатые абразивы - орудия, с помощью которых затачивались и выводились плоскости и грани металлического орудия. На Турганикском поселении обнаружены два экземпляра подобных орудий. Они представляют собой диск и плитку, которые, видимо, закреплялись в неподвижной деревянной основе (рис. 4,11,14).

Кроме того, в слое 5 Турганикского поселения найдены изделия из костей животных, в том числе 2 костяных наконечника, сопла, совок и рогатая булавка, обработанные с помощью медных орудий (рис. 5,7-11).

Помимо орудий Турганикского поселения трасологическим методом сделан анализ 9 каменных предметов из погребений ямной культуры Оренбуржья, которые ранее представлялись как просто песты. Все они типологически имеют схожую форму вытянутых пропорций, изготовлены из кремнистого известняка или из крупных окатанных галек. Оказа- 
лось, что из них 2 песта и плитка являлись орудиями для обработки растительного сырья, а остальные 6 изделий использовались в металлопроизводстве. При этом все находки сделаны в погребениях, где в массовом количестве обнаружены и сами медные орудия. Так, песты для дробления руды найдены в погр. 3 кург. 6 КМ Изобильное I (рис. 5,4) и в погр. 1 кург. 1 КМ Тамар-Уткуль VII (рис. 5,6). В последнем комплексе также обнаружены кузнечный молот и наковальня (рис. 5,3,1). Кузнечный молот в сочетании с гладилкой находился в погр. 7 кург. 4 КМ ТамарУткуль VII (рис. 5,2). Кузнечный молот также входил в комплект инвентаря наряду с медными и железными орудиями элитного погр. 1 кург. 1 могильника Болдырево I, одного из самых крупных курганов ямной культуры Приуралья (рис. 5,5). Однако следует оговориться, что в погребениях репинского этапа подобные орудия пока не известны.

\section{Заключение}

Трасологический анализ каменных макроорудий Турганикского поселения и погребений ямной культуры позволил получить весьма важные данные для реконструкции раннего этапа становления и развития металлургического производства на территории Приуралья. Впервые на массовом материале выявлены орудия, связанные с металлургией и металлообработкой раннего этапа ямной культуры. Среди изделий этого класса представлены орудия для всех этапов металлургического производства - от получения металла до завершения оформления готового медного изделия. При этом установлена прямая связь металлопроизводства на Турганикском поселении с сырьем, получаемым с Каргалинских рудников.

Поскольку фрагменты собственно руды в слое поселения обнаружены в незначительном количестве, а орудия для ее добычи (гор- нопроходческие) не найдены вовсе, то можно предположить, что процесс добычи и обогащения руды, вероятно, происходил на рудниках. По воде или вдоль р. Ток обогащенный концентрат доставлялся на место поселения, где получали металл и использовали его для отливки и изготовления орудий.

Исходя из того, что основой жизнеобеспечения населения ямной культуры являлось подвижное скотоводческое хозяйство, можно сделать следующий вывод: Турганикское поселение, видимо, являлось сезонной площадкой для производства металлических орудий - в основном в летнее время [Моргунова, 2014, с. 276-292]. Аналогичную экономическую стратегию исследователи предлагают для срубной и других степных культур позднего бронзового века [Антипина, Моралес, 2005, с. 41; Ткачев, 2020, с. 122]. Что характерно, в достаточно удаленных друг от друга памятниках поздней бронзы типология орудий металлопроизводства и сырье, из которого они изготавливались, практически идентичны и сходны с наборами орудий из Турганикского и Михайловского поселений, относящихся к гораздо более раннему времени [Килейников, 1984; Ержанова, 2020].

Таким образом, полученные результаты трасологического анализа позволяют достаточно уверенно делать вывод, что начальный период функционирования приуральского очага металлургии и металлопроизводства относится к репинскому этапу ямной культуры. По данным радиоуглеродного датирования слоя 5 Турганикского поселения, этот процесс мог начаться в первые века IV тыс. до н.э.

\section{ПРИМЕЧАНИЕ}

1 Работа выполнена при поддержке гранта РФФИ, проект № 18-09-40031 «Древности».

The work was supported by RFBR grant No. 18-09-40031 “Antiquities”. 


\section{ИЛЛЮСТРАЦИИ}

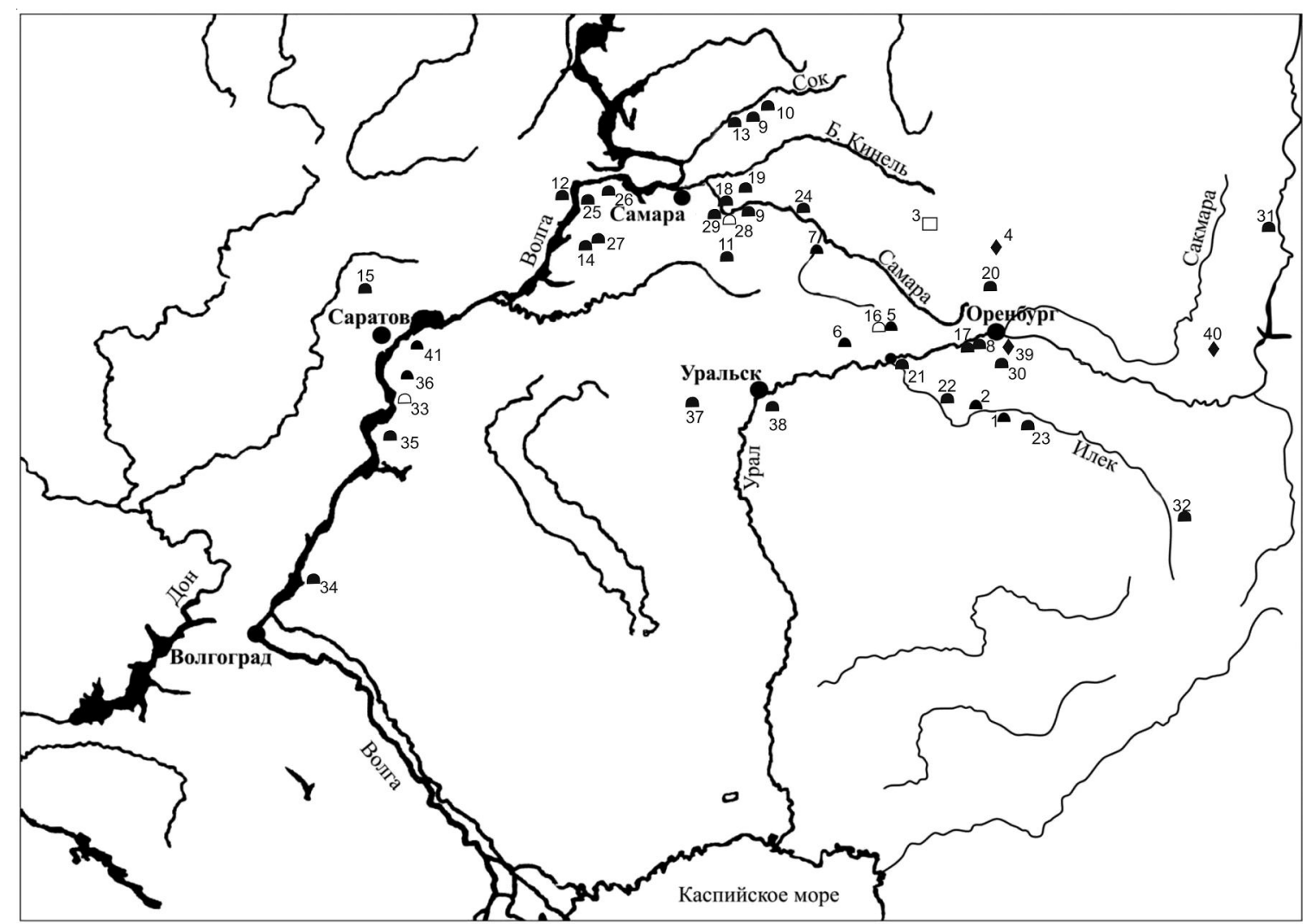

Условные обозначения:

-рудники

$\square \square$ - поселения и курганы раннего (репинского) этапа

- курганы развитого и позднего этапов

Рис. 1. Карта-схема. Памятники ямной культуры Волго-Уральского междуречья с находками медных изделий и древние рудники Южного Приуралья:

1 - Тамар-Уткуль VII, кург. 1, 3, 4, 6, 8, Тамар-Уткуль VIII, кург. 4, 5, 8; 2 - Изобильное I, кург. 3; 3 - пос. Турганикское; 4 - Каргалинские рудники; 5 - Мустаево V, кург. 8, 9; 6 - Болдырево I, кург. 1, 2, 10, Болдырево IV, кург. 2, 3;

7 - Скворцовка, кург. 5-7; 8 - Нижняя Павловка V, кург. 1; 9 - Лещевка I, кург. 2; 10 - Калиновка I, кург. 1; 11 - Орловка I, кург. 2; 12 - Уваровка II, кург. 2; 13 - Нижняя Орлянка I, кург. 1; 14 - Абашево, кург. 2; 15 - Сторожевка, кург. 1; 16 - Герасимовка II, кург. 4, хут. Барышников, кург. 6; 17 - Пятилетка, кург. 5; 18 - Красносамарское I, кург. 1, 2;

19 - Кутулук I, кург. 4; 20 - Першин, кург. 1; 21 - Илекский, кург. 2; 22 - Линевка III, кург. 1; 23 - Увакский, кург. 12; 24 - погр. у с. Колтубанка; 25 - Кашпир III, кург. 1; 26 - Преполовенка I, кург. 8; 27 - Владимировка, кург. 1; 28 - Покровка II, кург. 12, 17; 29 - Утевка I, кург. 1-3; 30 - Донгуз II, кург. 2; 31 - Мало-Кизильский II, кург. 1;

32 - Жаман-Каргала, кург. 1; 33 - Скатовка, кург. 5; 34 - хуг. Степана Разина, кург. 4; 35 - Ровное; 36 - Старая Полтавка; 37 - Светлое Озеро, кург. 1; 38 - Илекшар I, кург. 5; 39 - Сайгачий рудник; 40 - Ишкиновский рудник; 41 - Энгельс, кург. 2 (карта-схема составлена авторами по: [Мерперт, 1974, рис. 2; Моргунова, 2014, рис. 1])

Fig. 1. Schematic map. Monuments of the Yamnaya culture of the Volga-Ural interfluve with finds of copper tools:

1 - Tamar-Utkul VII, kurgans 1, 3, 4, 6, 8, Tamar-Utkul VIII, kurgans 4, 5, 8; 2 - Izobilnoe I, kurgan 3; 3 - Turganikskoye set.; 4 - Kargalinsky mines; 5 - Mustaevo V, kurgans 8, 9; 6- Boldyrevo I, kurgans 1, 2, 10, Boldyrevo IV, kurgans 2, 3; 7 - Skvortsovka, kurgans 5-7; 8- Nizhnyaya Pavlovka V, kurgan 1;9- Leshchevka I, kurgan 2; 10 - Kalinovka I, kurgan 1; 11 - Orlovka I, kurgan 2;

12 - Uvarovka II, kurgan 2; 13 - Nizhnyaya Orlyanka I, kurgan 1; 14 - Abashevo, kurgan 2; 15 - Storozhevka, kurgan 1;

16 - Gerasimovka II, kurgan 4, Barushnikov Farm, kurgan 6; 17 - Pyatiletka, kurgan 5; 18 - Krasnosamarskoe I, kurgans 1, 2;

19 - Kutuluk I, kurgan 4; 20 - Pershin, kurgan 1; 21 - Ileksky, kurgan 2; 22 - Linevka III, kurgan 1; 23 - Uvaksky, kurgan 12; 24 - burial Koltubanka; 25 - Kashpir III, kurgan 1;26 - Prepolovenka I, kurgan 8; 27 - Vladimirovka, kurgan 1;

28 - Pokrovka II, kurgans 12, 17; 29 - Utevka I, kurgans 1-3; 30 - Donguz II, kurgan 2; 31 - Malo-Kizilsky II, kurgan 1; 32 - Zhaman-Kargala, kurgan 1; 33 - Skatovka, kurgan 5; 34 - Stepan Razin's Farm, kurgan 4; 35 - Rovnoye; 36 - Staraya Poltavka; 37 - Svetloye Lake, kurgan 1; 38 - Ilekshar I, kurgan 5; 39 - Saigachy mine; 40 - Ishkinovsky mine; 41 - Engels, kurgan 2 (the schematic map was compiled by the authors after: [Merpert, 1974, fig. 2; Morgunova, 2014, fig. 1]) 

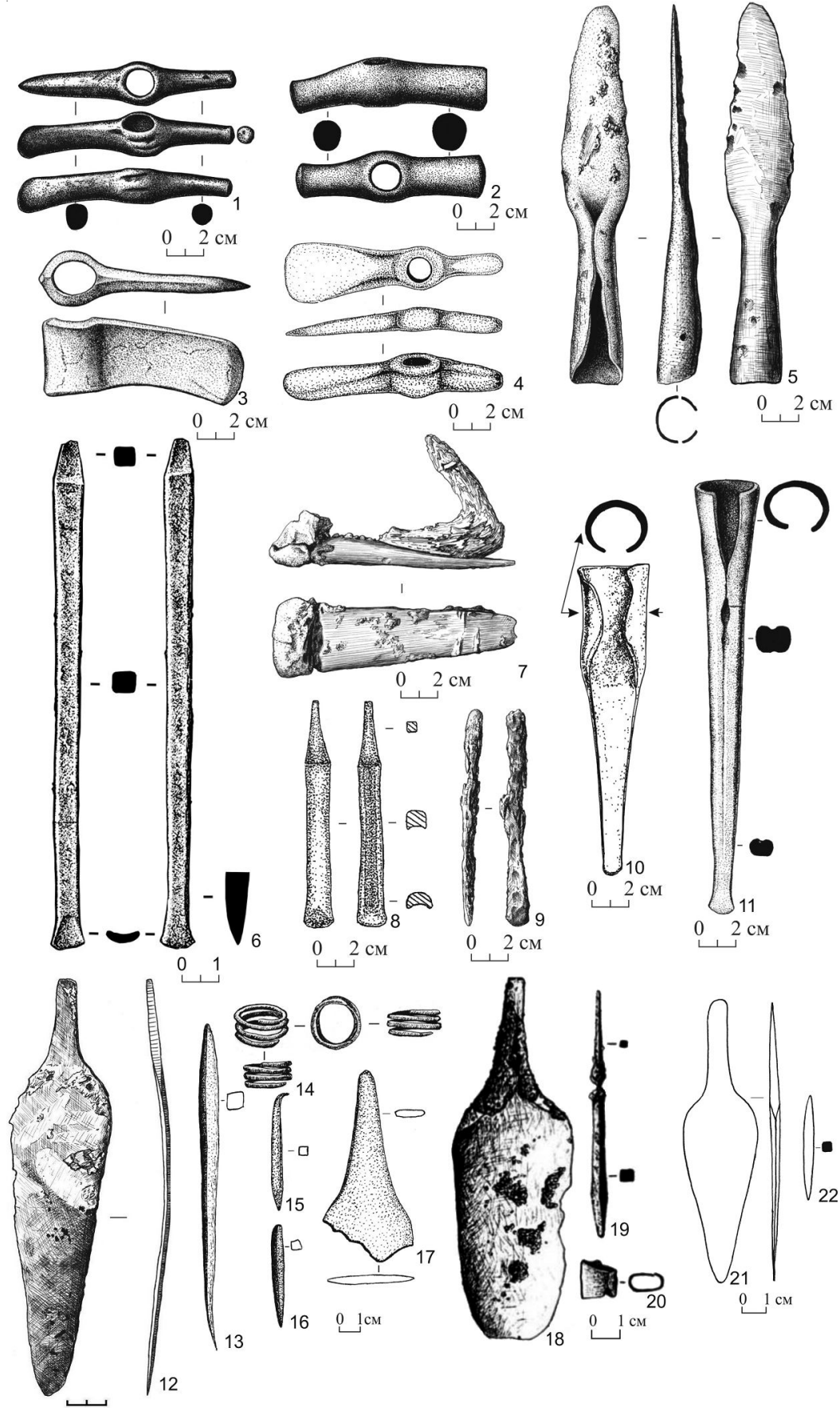

Рис. 2. Основные типы медных изделий из памятников ямной культуры Южного Приуралья

Памятники развитого этапа: 1 - Нижняя Павловка V, кург. 1, погр. 2; 2 - Увак, кург. 12, погр. 4; 3 - Тамар-Уткуль VII, кург. 8, погр. 4; 4 - у хуг. Барышников, кург. 6, погр. 3; 5 - Болдырево I, кург. 1, погр. 1; 6 - Пятилетка, кург. 5, погр. 2;

7 - Болдырево I, кург. 1, погр. 1; 8 - хут. Барышников, кург. 6, погр. 3; 9 - Болдырево I, кург. 1, погр. 1;

10 - Мустаево V, кург. 1, погр. 1; 11 - Тамар-Уткуль VII, кург. 8, погр. 4; 12 - Болдырево IV, кург. 2, погр. 1. Памятники раннего (репинского) этапа: 13-17 - пос. Турганикское; 18-20 - Герасимовка II, кург. 4, погр. 2; 21-22 - Покровка II, кург. 17, погр. 1 (по: [Моргунова, 2014])

Fig. 2. The main types of copper items from the monuments of the Yamnaya culture of the Southern Urals

Monuments of the advanceed stage: 1 - Nizhnyaya Pavlovka V, kurgan 1, burial 2; 2 - Uvak, kurgan 12, burial 4; 3 - Tamar-Utkul VII, kurgan 8, burial 4; 4 - Farm Baryshnikov, kurgan 6, burial 3; 5 - Boldyrevo I, kurgan 1, burial 1; 6 - Pyatiletka, kurgan 5, burial 2; 7 - Boldyrevo I, kurgan 1, burial 1; 8 - Farm Baryshnikov, kurgan 6, burial 3; 9 - Boldyrevo I, kurgan 1, burial 1; 10 - Mustaevo V, kurgan 1, burial 1; 11 - Tamar-Utkul VII, kurgan 8, burial 4; 12 - Boldyrevo VI, kurgan 2, burial 1. Monuments of the early (Repinsky) stage: 13-17- settlement Turganikskoe; 18-20 - Gerasimovka II, kurgan 4, burial 2; 21-22 - Pokrovka II, kurgan 17, burial 1 (after: [Morgunova, 2014]) 

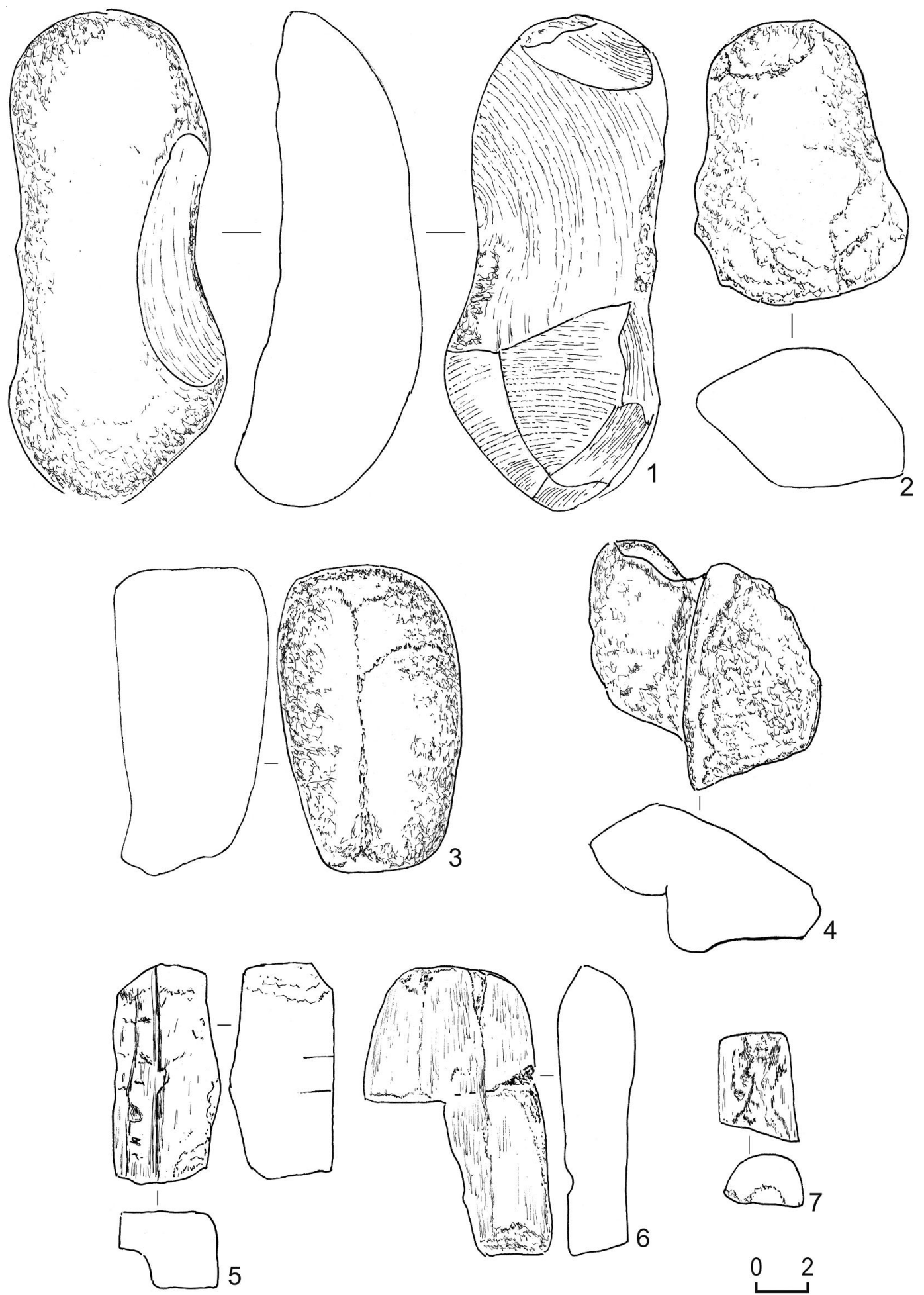

Рис. 3. Каменные орудия для металлургии, поселение Турганикское (рисунки выполнены И.В. Горащуком):

1-2 - молоты для дробления медной руды, крепившиеся на рукояти; 3 - каменный молот с ручным удержанием; 4 - рудотерка; 5-7 - литейная форма

Fig. 3. Stone tools for metallurgy, Turganik settlement (drawings by I.V. Goraschuk): 1-2 - hammers for crushing copper ore, attached to the handle; 3 - hand held stone hammer; 4 - ore mortar; 5-7 - casting mold 

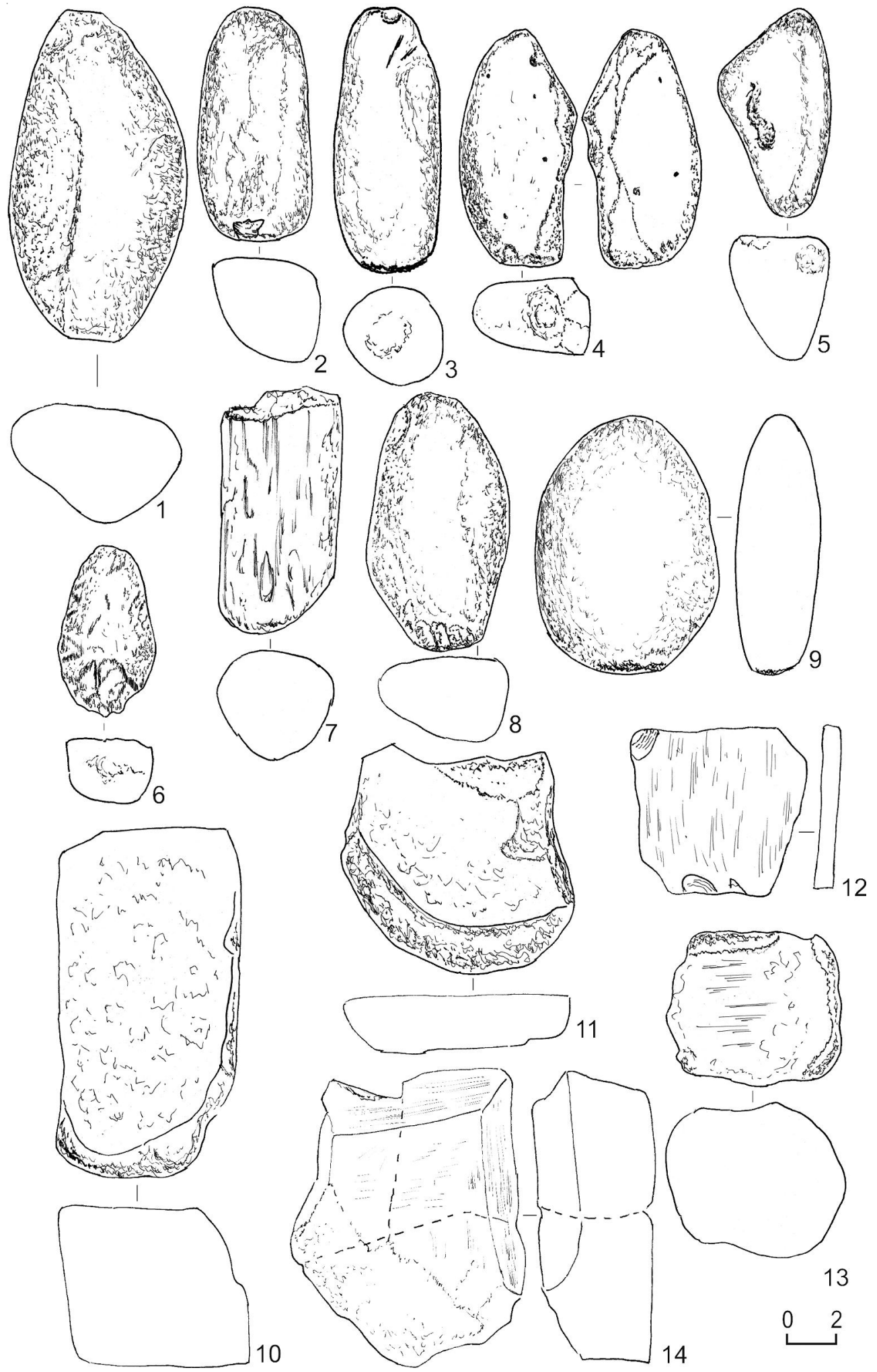

Рис. 4. Каменные орудия для металлообработки, поселение Турганикское (рисунки выполнены И.В. Горащуком):

1-9 - кузнечные молоты; 10 - наковальня; $11,13,14$ - орудия для выравнивания граней; 12 - оселок

Fig. 4. Stone tools for metalworking, Turganik settlement (drawings by I.V. Goraschuk): 1-9- blacksmith's hammers; 10 - anvil; $11,13,14$ - tools for leveling edges; 12 - touchstone 


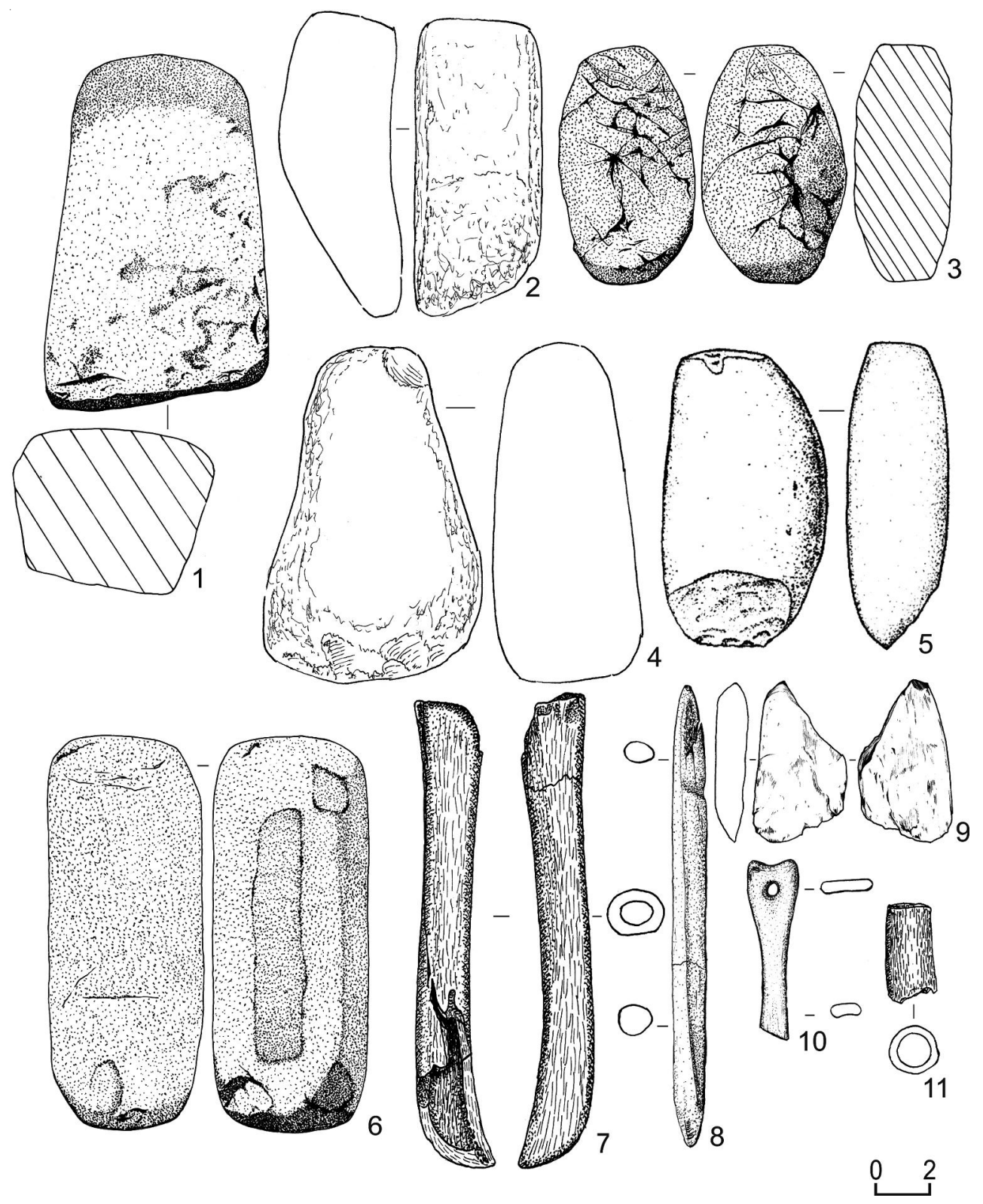

Рис. 5. Каменные орудия для металлопроизводства из памятников ямной культуры Южного Приуралья (рисунки выполнены авторами):

1 - наковальня (Тамар-Уткуль VII, кург. 1, погр.1); 2 - кузнечный молот и гладилка (Тамар-Уткуль VII, кург. 4, погр. 7); 3 - кузнечный молот (Тамар-Уткуль VII, кург. 1, погр. 1); 4 - пест для дробления руды (Изобильное, кург. 6, погр. 3); 5 - кузнечный молот (Болдырево I, кург. 1, погр. 1); 6 - молот для дробления руды (Тамар-Уткуль VII, кург. 1, погр. 1).

Турганикское поселение: 8,10 - костяные орудия со следами обработки металлическими инструментами; 9 - старательский совок из кости; 7, 11 - костяные сопла

Fig. 5. Stone tools for metal production from the sites of the Yamnaya culture of the Southern Urals (drawn by authors):

1 - anvil (Tamar-Utkul VII, kurgan 1, burial 1); 2 - forging hammer and trowel (Tamar-Utkul VII, kurgan 4, burial 7); 3 - forging hammer (Tamar-Utkul VII, kurgan 1, burial 1); 4 - hammer for ore crushing (Izobilnoye, kurgan 6, burial 3); 5 - forging hammer (Boldyrevo I, kurgan 1, burial 1); 6 - hammer for ore crushing (Tamar-Utkul VII, kurgan 1, burial 1). Turganik settlement: 8,10 - bone tools with traces of processing by metal tools; 9 - bone prospectors scoop; 7,11- bone nozzles 


\section{СПИСОК ЛИТЕРАТУРЫ}

Антипина Е. Е., Моралес А., 2005. «Ковбои» восточноевропейской степи в позднем бронзовом веке // OPUS : Междисциплинарные исследования в археологии. Вып. 4. М. : ИА РАН. С. 29-44.

Богданов С. В., 2019. Технологии горно-металлургического производства эпохи раннего металла Северной Евразии с позиций экспериментальной археологии // Феномены культур раннего бронзового века степной и лесостепной полосы Евразии: пути культурного взаимодействия в V-III тыс. до н.э. Оренбург : Изд-во ОГПУ. С. 161-174.

Васильев И. Б., Кузнецов П. Ф., Турецкий М. А., 2000. Ямная и полтавкинская культуры // История Самарского Поволжья с древнейших времен до наших дней. Бронзовый век. Самара : Самар. науч. центр РАН. C. 6-64.

Дегтярева А. Д., 2010. История металлопроизводства Южного Зауралья в эпоху бронзы. Новосибирск : Наука. $162 \mathrm{c}$.

Ержанова А. Е., 2020. Каменные орудия металлургов : типология, трасология // Талдысай - поселение древних металлургов позднебронзового века в Улытауской степи. Алматы : Ин-т археологии А.Х. Маргулана. С. $103-135$.

Каргалы, 2004. Т. III: Селище Горный : Археологические материалы. Технология горно-металлургического производства. Археобиологические исследования. М. : Яз. славян. культуры. 320 с.

Каргалы, 2005. T. IV: Некрополи на Каргалах; население Каргалов : палеоантропологические исследования. М. : Яз. славян. культуры. 240 с.

Килейников В. В., 1984. Каменные горнометаллургические и металлообрабатывающие орудия Мосоловского поселения // Эпоха бронзы восточноевропейской лесостепи. Воронеж : Изд-во ВГУ. С. 110-120.

Коробкова Г. Ф., Шапошникова О. Г., 2005. Поселение Михайловка - эталонный памятник древнеямной культуры. СПб. : Европейский Дом. 316 с.

Мерперт Н. Я., 1974. Древнейшие скотоводы Волжско-Уральского междуречья. М. : Наука. 166 с.

Моргунова Н. Л., 2014. Приуральская группа памятников в системе волжско-уральского варианта ямной культурно-исторической области. Оренбург : Изд-во ОГПУ. 348 с.

Моргунова Н. Л., Васильева И. Н., Кулькова М. А., Рослякова Н. В., Салугина Н. П., Турецкий М. А., Файзуллин А. А., Хохлова О. С., 2017. Турганикское поселение в Оренбургской области. Оренбург : Издательский центр ОГАУ. 299 с.

Моргунова Н. Л., Файзуллин А. А., 2018. Социальная структура ямной культуры Волжско-Уральского междуречья // Stratum Plus. № 2. С. 35-60.

Орловская Л. Б., 1994. Цветной металл Болдыревского I могильника // Моргунова Н. Л., Кравцов А. Ю. Памятники древнеямной культуры на Илеке. Екатеринбург : Наука. С. 112-115.

Рысин М. Б., 2007. Связи Кавказа с волго-уральским регионом // Археологические вести. № 14. С. 184-220.

Ткачев В. В., 2020. Трансграничная зона срубной и алакульской культур в степном Приуралье : физико-географический и горно-металлургический аспекты // Поволжская археология. № 3 (33). С. 116-127.

Федорова-Давыдова Э. А., 1962. Новые памятники неолита и бронзы в Оренбургской области // Вопросы археологии Урала. № 2. Свердловск : Изд-во Урал. гос. ун-та. С. 16-20.

Черных Е. Н., 1966. История древнейшей металлургии Восточной Европы. М. : Наука. 144 c.

Черных Е. Н., 1970. Древнейшая металлургия Урала и Поволжья. М. : Наука. 180 с.

\section{REFERENCES}

Antipina E.E., Morales A., 2005. «Kovboi» vostochnoevropeyskoy stepi v pozdnem bronzovom veke ["Cowboys" of the Eastern European Steppe in the Late Bronze Age]. OPUS: Mezhdisciplinarnye issledovaniya $v$ arheologii [OPUS: Interdisciplinary Research in Archeology], iss. 4. Moscow, IA RAN, pp. 29-44.

Bogdanov S.V., 2019. Tekhnologii gorno-metallurgicheskogo proizvodstva epohi rannego metalla Severnoy Evrazii s pozitsiy eksperimental'noy arkheologii [Technologies of Mining and Metallurgical Production of the Early Metal Era of Northern Eurasia from the Standpoint of Experimental Archaeology]. Fenomeny kul tur rannego bronzovogo veka stepnoy i lesostepnoy polosy Evrazii: puti kul'turnogo vzaimodeystviya v V-III tys. 
do n.e. [Phenomena of the Cultures of the Early Bronze Age of the Steppe and Forest-Steppe Zone of Eurasia: Ways of Cultural Interaction in the $5^{\text {th }}-3^{\text {rd }}$ Millennium BC]. Orenburg, OSPU, pp. 161-174.

Vasiliev I.B., Kuznetsov P.F., Turetskiy M.A., 2000. Ymnaya i poltavkinskaya kul'tury [Yamnaya and Poltava Culture]. Istoriya Samarskogo Povolzh'ya s drevneyshih vremen do nashih dney. Bronzovyy vek [History of the Samara Volga Region from Ancient Times to the Present Day. Bronze Age]. Samara, Samara Scientific Center RAS, pp. 6-64.

Degtyareva A.D., 2010. Istoriya metalloproizvodstva Yuzhnogo Zauralya v epohu bronzy [Metal Production History of the Southern Trans-Urals in the Bronze Age]. Novosibirsk, Nauka Publ. 162 p.

Erzhanova A.E., 2020. Kamennye orudiya metallurgov: tipologiya, trasologiya [Stone Tools of Metallurgists: Typology, Traceology]. Taldysay - poselenie drevnih metallurgov pozdnebronzovogo veka v Ulytauskoy stepi [Taldysay - Settlement of Ancient Metallurgists of the Late Bronze Age in the Ulytau Steppe]. Almaty, Institute of Archaeology named after A.Kh. Margulan, pp. 103-135.

Kargaly, 2004. Vol. III: Selishche Gornyy: Arkheologicheskie materialy: Tekhnologiya gorno-metallurgicheskogo proizvodstva: arkheobiologicheskie issledovaniya [Gorny Site: Archaeological Materials: Mining and Metallurgy: Archaeobiological Studies]. Moscow, Yazyki slavianskoy kul’tury Publ. 320 p.

Kargaly, 2005. Vol. IV: Nekropoli na Kargalah; naselenie Kargalov: paleoantropologicheskie issledovaniya [Kargaly Necropolis; Kargaly Populations Paleoanthropological investigation]. Moscow, Yazyki slavianskoy kul'tury Publ. 240 p.

Kileynikov V.V., 1984. Kamennye gornometallurgicheskie i metalloobrabatyvayushchie orudiya Mosolovskogo poseleniya [Stone Mining and Metallurgical and Metalworking Tools of the Mosolovskiy Settlement]. Epoha bronzy vostochnoevropeyskoy lesostepi [The Bronze Age of the East European Forest-Steppe]. Voronezh, VSU, pp. 110-120.

Korobkova G.F., Shaposhnikova O.G., 2005. Poselenie Mikhaylovka - etalonnyy pamyatnik drevneyamnoy kul 'tury [The Settlement of Mikhailovka is a Reference Monument of the Ancient Pit Culture]. St. Petersburg, Evropeiskiy Dom Publ. 316 p.

Merpert N.Ya. 1974. Drevneishie skotovodi Voljsko-Uralskogo mejdurechya [Ancient Cattle Farmers of the VolgaUral Interfluve]. Moscow, Nauka Publ. 166 p.

Morgunova N.L., 2014. Priuralskaya gruppa pamyatnikov v sisteme volzhsko-uralskogo varianta yamnoy kulturno-istoricheskoy oblasti [The Cis-Urals Group of Archaeological Monuments of the Volga-Ural Variety of Yamna Cultural-Historical Area]. Orenburg, OSPU. 348 p.

Morgunova N.L., Vasil'eva I.N., Kul'kova M.A., Roslyakova N.V., Salugina N.P., Turetskiy M.A., Fayzullin A.A., Khohlova O.S., 2017. Turganikskoe poselenie v Orenburgskoy oblasti [Turganik Settlement in the Orenburg Region]. Orenburg, Orenburg State Agricultural University. 299 p.

Morgunova N.L., Faizullin A.A., 2018. Sotsialnaya struktura yamnoy kultury Volzhsko-Uralskogo mezhdurechya [The Social Structure of the Yamnaya (Pit-Grave) Culture of the Volga-Ural Interfluve]. Stratum Plus, no. 2 , pp. 35-60.

Orlovskaya L.B., 1994. Tsvetnoy metall Boldyrevskogo I mogil'nika [Non-ferrous Metal of Boldyrevskyi I Cemetery]. Morgunova N.L., Kravtsov A.Yu. Pamyatniki drevneyamnoy kul'tury na Ileke [Monuments of Ancient PitGrave Culture on Ilek]. Ekaterinburg, Nauka Publ., pp. 112-115.

Rysin M.B., 2007. Svyazi Kavkaza s Volgo-Ural'skim regionom [Connections of the Caucasus with the Volga-Ural Region]. Arkheologicheskie vesti [Archeological News], no. 14, pp. 184-220.

Tkachev V.V., 2020. Transgranichnaya zona srubnoy i alakul'skoy kul'tur v stepnom Priural'e: fiziko-geograficheskiy i gorno-metallurgicheskiy aspekty [Crossborder Zone of Srubnaya and Alakul Cultures in the Steppe PreUrals: Physical-Geographical and Mining-Metallurgical Aspects]. Povolzhskaya archeology [The Volga River Region Archaeology], no. 3 (33), pp. 116-127.

Fedorova-Davydova E.A., 1962. Novye pamyatniki neolita i bronzy v Orenburgskoy oblasti [New Neolithic and Bronze Monuments in the Orenburg Region]. Voprosy arkheologii Urala [Archeological issues of the Urals], no. 2. Sverdlovsk, Ural State University, pp. 16-20.

Chernykh E.N., 1966. Istoriya drevneyshey metallurgii Vostochnoy Evropy [History of the Ancient Metallurgy in Eastern Europe]. Moscow, Nauka Publ. 144 p.

Chernykh E.N., 1970. Drevneyshaya metallurgiya Urala i Povolzh'ya [The most Ancient Metallurgy of the Urals and the Volga Region]. Moscow, Nauka Publ. 180 p. 
Н.Л. Моргунова, А.А. Файзуллин. Новые данные о начале функционирования Приуральского ГМЦ

\section{Information About the Authors}

Nina L. Morgunova, Doctor of Science (History), Professor, Leading Researcher, Archaeological Laboratory, Orenburg State Pedagogical University, Sovetskaya St, 19, 460014 Orenburg, Russian Federation, nina-morgunova@yandex.ru, https://orcid.org/0000-0002-8091-7411

Airat A. Faizullin, Candidate of Science (History), Junior Researcher, Archaeological Laboratory, Orenburg State Pedagogical University, Sovetskaya St, 19, 460014 Orenburg, Russian Federation, faizullin.airat@yandex.ru, https://orcid.org/0000-0003-0658-0547

\section{Информация об авторах}

Нина Леонидовна Моргунова, доктор исторических наук, профессор, главный научный сотрудник археологической лаборатории, Оренбургский государственный педагогический университет, ул. Советская 19, 460014 г. Оренбург, Российская Федерация, nina-morgunova@yandex.ru, https://orcid.org/0000-0002-8091-7411

Айрат Асхатович Файзуллин, кандидат исторических наук, младший научный сотрудник археологической лаборатории, Оренбургский государственный педагогический университет, ул. Советская 19, 460014 г. Оренбург, Российская Федерация, faizullin.airat@yandex.ru, https://orcid.org/0000-0003-0658-0547 